\title{
Land reforms and population growth
}

\author{
Ulla Lehmijoki ${ }^{1,2}$ • Tapio Palokangas ${ }^{1,2,3}$
}

Received: 28 October 2014 / Accepted: 16 February 2016 / Published online: 14 March 2016 (c) The Author(s) 2016. This article is published with open access at Springerlink.com

\begin{abstract}
One of the greatest puzzles in demographic history is why in the rich and urbanized England, fertility declined much later than in the poor and rural France. We consider the effects of a land reform on demographic growth by a familyoptimization model where relative per capita wealth generates social status and welfare. We show that tenant farming is the major obstacle to escaping the Malthusian trap with high fertility and low productivity. A land reform provides peasants with higher returns for their investments, inducing them to increase their productivity and status rather than their family size. Consequently, the population growth rate slows down, but the productivity of land increases.
\end{abstract}

Keywords Land reforms - Population growth - Status - Relative wealth · Sharecropping

JEL Classification $\mathrm{O} 41 \cdot \mathrm{J} 13 \cdot \mathrm{N} 33$

\section{Introduction}

One of the greatest puzzles in demographic history is why in the rich and urbanized England, fertility declined much later than in the poor and rural France. This article

$\triangle$ Tapio Palokangas

tapio.palokangas@helsinki.fi

Ulla Lehmijoki

ulla.lehmijoki@helsinki.fi

1 HECER, University of Helsinki, P.O. Box 17 (Arkadiankatu 7), Helsinki, 00014 Finland

2 IZA, Bonn, Germany

3 IIASA, Schlossplatz 1, A-2361 Laxenburg, Austria 
considers the role of land ownership in increasing the productivity of land and limiting the family size. Land reforms can slow down population growth, in particular, where relative per capita wealth generates welfare through social status. We propose that the land reform associated with the Great French Revolution may explain the French-English fertility paradox.

Malthus (1798) was the first one to pay attention to the relationship between growing population and fixed land. Lucas (2002) demonstrates this relationship by human history as follows. In primitive societies, where land was commonly owned, parents could not improve the position of their descendants. Once the property rights for land were established, parents could determine the optimal number of children to whom they transfer their land. With private ownership, each newcomer decreases income per capita, thus slowing down the desired population growth. Galor et al. (2009) consider the detrimental role of unequal land ownership. Because the landed aristocracy benefits from cheap labor, it executes its political power to retard overall education. Consequently, land reforms trigger modernization and demographic change.

In this article, we emphasize status seeking among peasant families, which plays an important role in population growth. Naturally, the idea of social factors dictating the fertility choice is not new. It was a central element already in Notestein's theory of demographic transition (Notestein 1945) and gained space as the Princeton Fertility Project indicated that the decline of fertility in Europe was mostly due to her cultural and lingual borders (Coale and Watkins 1986). Since that project, several authors also emphasized the role of new values established by in the Great French Revolution (Cleland and Wilson 1987; van de Kaa 1996; Acemoglu et al. 2010; Gonzàlez-Bailòn and Murphy 2013). This challenged the economic drivers of fertility change being proposed by Becker (1960), Easterlin (1975), and Galor and Weil (2000) and others.

Kurz (1968), Corneo and Jeanne (2001) and Fisher and Hof (2005) introduce the status effect - each household is better off if it has more wealth than its reference group on the average - as a component of a household's stable investment function. Lehmijoki and Palokangas $(2009,2010)$ examine the economic and demographic growth of developing countries by a family-optimization model. Lehmijoki and Palokangas (2014) consider the effect of land reforms on fertility, but unfortunately leaning on two admittedly strong assumptions: (i) peasant families can hire land from competitive markets at any time; and (ii) they are not obliged to pay any compensations to their former landowners after a land reform has taken place. In this article, we prefer to assume the following. First, landowners determine sharecropping independently, given tenants' expected behavior. Second, with the introduction of a land reform, sharecropping vanishes but the peasant families compensate this loss of income to their former landowners. This new setup is better in accordance with the realities of the 18th and 19th centuries.

The remainder of this article is organized as follows. Section 2 provides evidence on the European ferility paradox from England and France. Section 3 considers the behavior of the peasant family in a theoretical model with a status effect. Section 4 examines the effect of a land reform, illustrating the transition from the position of high fertility and low income to that of low fertility and high income. Section 5 summarizes the results. 
Cohort fertility rate (children per woman)

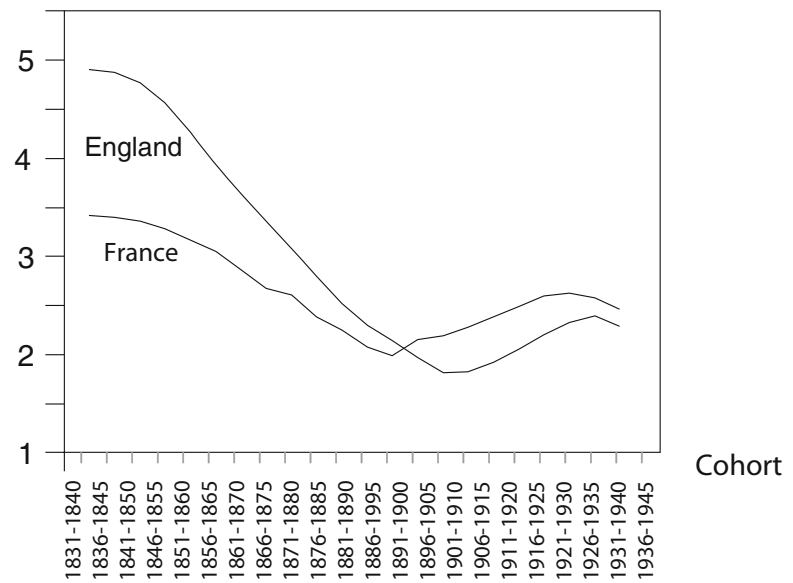

Fig. 1 The decline of fertility in France, England. Source: Festy (1979, pages 266-67, 262 and 222). But see also Bonneuil (1997) for somewhat higher estimates

\section{Land reforms and the French-English fertility paradox}

The French-English fertility paradox, i.e. the disparity of demographic and economic change of these countries, has puzzled many scientists (Coale 1986; Mokyr 2005; Guinnane 2011). On the basis of historical economic data, Chesnais (1992, p. 326) argues that, before the onset of modern economic growth, the level of income was approximately the same in France and England but once this onset took place, income levels diverged rapidly. Maddison (1995, pp. 194-196) estimates that already in 1820 the GDP per capita was in England almost twice as large as in France, and that this difference only increased during the remainder of that century. Thus, if the fertility decline was triggered by modern economic growth, then England should have proceeded long before France (Coale 1986). On the contrary, however, England had Industrial Revolution without Demographic Revolution while France had Demographic Revolution without Industrial Revolution (Chesnais 1992, 327-333).

Figure 1 illustrates the fertility trends from 1831 to 1945 in England and France showing that, in period 1831-1840, the fertility in England was over $40 \%$ higher than in France. In period 1831-1840, the fertility decline was well in progress in France but just beginning in England. ${ }^{1}$ Furthermore, it took over 30 years for England to reach the 1831-1840 numbers in France. What explains the low and rapidly decreasing fertility rate in France?

This paper emphasizes the role of the land reform that occurred during the Great French Revolution 1789-1799. Figure 3 presents the marital fertility rate in France

\footnotetext{
${ }^{1}$ The cohort fertility rate in Fig. 1 shows the total number of births given by women born in the time period indicated in the Figure.
} 


\section{GDP per capita (1991 international Geary-Khamis dollars)}

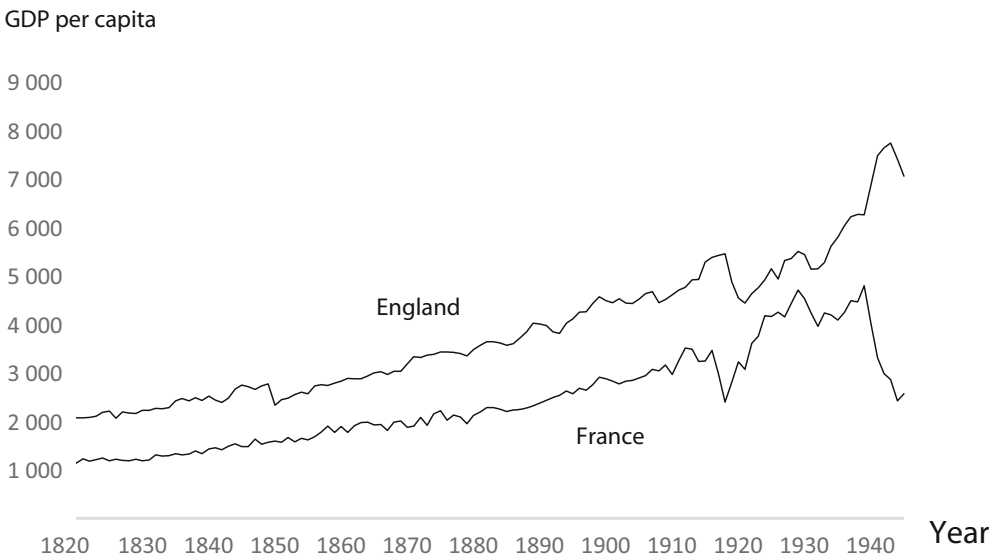

Fig. 2 The GDP per capita in France and England from 1820 to 1940. Source: The Maddison-Project (2013)

from 1740 to $1911 .^{2}$ Figure 3 shows that marital fertility declined sharply soon after the Great Revolution during which considerable sales of national property and sharing of common land took place. As a result, the number of small farms increased and, in 1830, landowning farmers represented $63 \%$ of the population in France, while only $14 \%$ in Britain (Chesnais 1992, p. 337). This widespread ownership of land was actually a unique feature of France.

As a consequence of the land reform, the farmers earn more from their land as they can keep a larger share of their crop by themselves. Thus, they have more incentives to invest in the productivity of land. Figure 2 illustrates the steady rise of GDP per capita in France. This was slower than in the rapidly industrializing England but yet considerable, facing the fact that France remain agrarian until the second World War. ${ }^{3}$ Sutherland (2002) also provides data which shows that there was some $30 \%$ improvement in total factor productivity in agriculture during the first decades after the Great Revolution (Fig. 3).

Per capita income can be increased also by limiting the family size. Accordingly, the fertility decline in France was just due to the declining demand for children among the peasants. However, there is evidence that the fertility control targeted not only for better income but also for social rise. Cummins (2013) combines early wealth and fertility data and observes the following: In villages where fertility was

\footnotetext{
${ }^{2}$ The concept of marital fertility is very useful, because it refers to the intentional and conscious behavior of couples (Mokyr 2005, p.1148). Marital fertility index is expressed as the share of the maximum fertility rate (1.00) for married women. Usually, the maximum is assumed to be one child every second or third year. The highest fertility rates are found among the Hutterites in Canada.

${ }^{3}$ From 1750 to 1928 , the per capita volume of the industrial production increased by factor 12 in England and by factor 9 in France, while the share of the agrarian labor force decreased from some $40 \%$ to less than $10 \%$ in the former but only from some $60 \%$ to some $40 \%$ in the latter (Bairoch 1982; Sullivan 1995).
} 
Fig. 3 The marital fertility rate in France. Source: Weir (1994)
Marital fertility rate in France

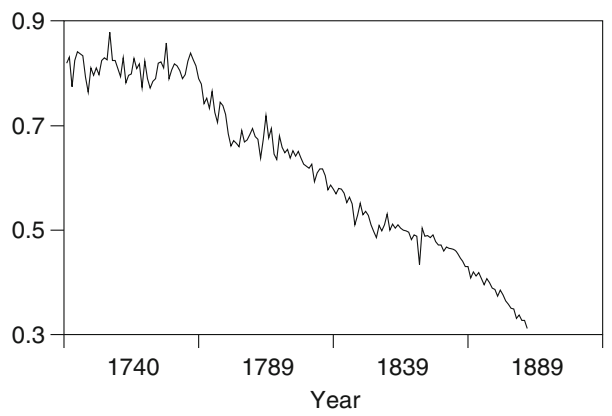

still high, wealth and fertility were positively associated, which suggests that the desire for having children ${ }^{4}$ dominated the status effect of per capita wealth. ${ }^{5}$ In contrast, in villages where fertility is low and even declining, this association was negative, indicating that the status effect of per capita wealth was strong enough to outweigh the desire for children. ${ }^{6}$ The Great Revolution eliminated the old elites and paved the way to the new rural bourgeoisie class. This class soon realized the potential of fertility control as a device of supporting its progress in the society (Cummins 2013).

\section{Peasants and landowners}

We examine a one-good economy. The price of the good is normalized at unity in the model. There are two agents: the representative peasant family, which produces the good from land and labor, derives utility from its consumption, the number of its children and from its social status determined by its wealth relative to the other peasant families, and invests in agricultural technology to improve the productivity of the land it cultivates; and the representative landowner, which consumes all of its rents it collects from the peasant family.

The peasant family has $L(t)$ members at time $t$. Its (net) fertility rate $n$ is

$$
n \doteq \frac{\dot{L}}{L} \doteq \frac{1}{L} \frac{d L}{d t},
$$

where $\left({ }^{\circ}\right)$ is the time derivative. The family improves the productivity of land, $A$, by its investment $I$ :

$$
\dot{A} \doteq \frac{d A}{d t}=I
$$

\footnotetext{
${ }^{4}$ This is charaterized by $\theta$ in the utility function (10).

${ }^{5}$ This is charaterized by $\varepsilon$ in the utility function (10).

${ }^{6}$ Fertility differentials between rich and poor may also refer to educational differentials (de la Croix and Doepke 2003), but this was unlikely in the rural France.
} 
We normalize the area of land at unity, so that the input of efficient land equals $A$. The number of family members employed in child rearing, $q n L$, is in fixed proportion $q$ to total fertility $n L$ at any time. The rest of the family,

$$
N \doteq L-q n L=(1-q n) L
$$

works in the family farm. The composite product $Y$ is made from labor input $N$ and efficient land $A$ according to neoclassical technology

$$
\begin{aligned}
& Y=F(N, A), \quad F_{N} \doteq \frac{\partial F}{\partial N}>0, \quad F_{A} \doteq \frac{\partial F}{\partial A}>0, \quad F_{N N} \doteq \frac{\partial^{2} F}{\partial N^{2}}<0, \\
& F_{A A} \doteq \frac{\partial F}{\partial A^{2}}<0, \quad F_{N A} \doteq \frac{\partial^{2} F}{\partial N \partial A}>0, \quad F \text { linearly homogeneous. }
\end{aligned}
$$

In many rural economies, child labor plays an important role. We could take this into account by extending the production function (4) into the form $Y=$ $F(N, A, n L)$, where $n L$ is the number of children. Because this would complicate the analysis with no qualitative improvements in the results, we ignore child labor in production in this study.

The landowner rents a farm out to the peasant family taking a share of the crop as a return. The peasant family hides some of its crop with costs and the landowner attempts to monitor this with costs. The interaction between these two agents implies that, in equilibrium, the peasant family earns (net of hiding costs) a fixed proportion $\alpha$ of its crop $Y$ as follows (cf. Appendix A):

$$
\alpha= \begin{cases}1 & \text { as an independent farmer, } \\ \gamma \in(0,1) & \text { as a tenant farmer. }\end{cases}
$$

Thus, a land reform increases the family's crop share $\alpha$ from $\gamma$ to 1 . In return, the landowner's lost wealth is compensated by a debt which the family repays over time. We assume that if a family is split into smaller families, then its debt is divided in proportion to family members. This allows us to define the debt in per capita terms. We furthermore assume that a fixed proportion $\beta$ of per capita debt $b$ will be repaid at each time, for simplicity: ${ }^{7}$

$$
\dot{b}=-\beta b .
$$

The family spends its income $\alpha Y$ on consumption $C$, investment $I$ and repayments $\beta b L$ of debt $b L$. Denoting consumption per capita by $c \doteq C / L$ and the productivity of land per capita by $a \doteq A / L$, and noting Eqs. 2, 3, 4 and 6, the family's budget constraint becomes

$$
\dot{A}=I=\alpha Y-C-\beta b L=\alpha F(N, A)-C-\beta b L=[\alpha F(1-q n, a)-c-\beta b] L .
$$

Noting $a \doteq A / L$, Eqs. 1 and 7, we obtain the per capita budget constraint

$$
\dot{a}=\frac{\dot{A}}{L}-\frac{\dot{L}}{L} \frac{A}{L}=\frac{\dot{A}}{L}-n a=\alpha F(1-q n, a)-c-\beta b-n a .
$$

\footnotetext{
${ }^{7}$ If the family could reallocate its consumption over time by choosing its repayment proportion $\beta$, then the analysis in Appendix B would become extremely complicated.
} 
Per capita output at time $t$ is $Y(t) / L(t)=F(1-q n(t), a(t))$ [cf. $a \doteq A / L$, (3) and (4)]. Let the landowner's rate of time preference be constant $\sigma>0$. On the assumption that the economy is in the steady state at time $t=0$, the present value of the landowner's per capita output is $F\left(1-q n_{0}, a_{0}\right) / \sigma$, where

$$
a_{0} \doteq \lim _{t \rightarrow 0-} a(t), \quad n_{0} \doteq \lim _{t \rightarrow 0-} n(t)
$$

are the predetermined values of $a$ and $n$ at time $t=0$. Of the present value of output, $F\left(1-q n_{0}, a_{0}\right) / \sigma$, the landowner forfeits the proportion $\alpha-\gamma$ if a land reform increases the peasant family's crop share $\alpha$ above $\gamma$ at time $t=0$ [cf. (5)]. Because the family compensates this loss to the landowner as a debt, the initial value for its per capita debt $b(t)$ at time $t=0$ is given by

$$
b(0)=(\alpha-\gamma) F\left(1-q n_{0}, a_{0}\right) / \sigma .
$$

\section{The effects of a land reform}

Following Razin and Ben-Zion (1975) and Becker (1960), we assume that the family derives temporary utility from the per capita consumption and the proportion of young in the family, $n$ (= the fertility rate), which characterizes the status provided by children in a rural society. Because the peasant family saves only by investing in land, the input of efficient land per capita, $a \doteq A / L$, is a proper measure of its per capita wealth. A single family has the higher status, the higher input of efficient land per capita it has (i.e. the higher $a \doteq A / L$ ) relative to that among all families on the average, $\underline{a}$. Thus, we augment the temporary utility by an increasing function $v(a-\underline{a})$ of the difference $a-\underline{a} .{ }^{8}$ The temporary utility is therefore given by

$$
u(t)=\log c+\theta \log n(t)+\varepsilon v(a(t)-\underline{a}(t)),
$$

where $\theta>0$ and $\varepsilon>0$ are the constant weights for children and status. The bigger $\varepsilon$, the more relative wealth, and the bigger $\theta$, the more children the family should like to have. Noting temporary utility (10), the peasant family's expected utility at time $t=0$ is

$$
\begin{aligned}
& U=\int_{0}^{\infty} u(t) e^{-\rho t} d t=\int_{0}^{\infty}[\log c+\theta \log n+\varepsilon v(a-\underline{a})] e^{-\rho t} d t, \\
& v^{\prime}>0, \quad v^{\prime \prime}<0, \quad v^{\prime}(0)=1, \quad \rho>0, \quad \theta>0,
\end{aligned}
$$

where the constant $\rho>0$ is the family's rate of time preference.

The status-effect (as characterized by the parameter $\varepsilon$ ) plays a crucial role in the model, and we assume that it is strong enough relative to the desire for having children (as characterized by the parameter $\theta$ ) so that the following inequality holds true:

$$
\frac{\varepsilon}{\theta}>\max \left[\frac{1}{a}, \quad \frac{1}{a} \frac{1-q n}{q n}\right],
$$

\footnotetext{
${ }^{8}$ This specification is chosen for simplicity. If the measure $v$ were a linearly homogeneous function of $a$ and $\underline{a}$, we would obtain the same results with some complication.
} 
where $\frac{1}{a}$ is labor per efficient land and $\frac{1-q n}{q n}$ the ratio of labor in production relative to labor in child rearing. In addition, we assume that the repayment rate $\beta$ of the debt is slow enough for

$$
\begin{aligned}
& \beta<\left(1-\frac{\eta}{\theta}\right) \sigma \text { with } \\
& \eta \doteq \frac{n F_{N}(N, A)}{F(N, A)} \frac{\partial N}{\partial n}=-\frac{n F_{N}(N, A)}{F(N, A)} q L=-\frac{q n F_{N}(1-q n, a)}{F(1-q n, a)}<0,
\end{aligned}
$$

where $\sigma$ is the landowner's rate of time preference, $\theta$ the peasant family's weight for children [cf. (11)] and $\eta$ the elasticity of output $Y$ with respect to the birth rate $n$, holding efficient land $A$ constant [cf. (3) and (4)].

A land reform increases the peasant family's crop share $\alpha$ from $\gamma \in(0,1)$ to 1 . First, we consider the effect of $\alpha$ on the assumption that $\alpha \in[\gamma, 1]$ is a continuous variable. The reform increases both the crop share $\alpha$ and the initial debt (9) for the family at time $t=0$. The family then maximizes its utility (11) by choosing its fertility $n$ and consumption per capita, $c$, subject to its budget constraint (8) and the repayment of debt, (6). Conditional on assumptions Eqs. 12 and 13, the solution of this maximization leads to the following results (cf. Appendix B):

$$
\frac{d a^{*}}{d \alpha}>0, \quad \frac{d n^{*}}{d \alpha}<0,
$$

where $a^{*}$ and $n^{*}$ are the steady-state values for $a$ and $n$. The results (14) can be rephrased as follows:

Proposition 1 In the long run, a marginal increase of the peasant family's crop share $\alpha$ increases per capita efficient land $a^{*}$, but decreases the fertility rate $n^{*}$.

Because results (14) hold for all values $\alpha \in[\gamma, 1]$, Proposition 1 can be generalized for the discrete choice $\alpha \in\{\gamma, 1\}$ as well:

Proposition 2 In the long run a land reform, where a tenant farmer with $\alpha=\gamma<1$ becomes an independent farmer with $\alpha=1$, increases per capita efficient land $a^{*}$, but decreases the fertility rate $n^{*}$.

An increase of the crop share $\alpha$ raises the rate of return for investment in land. This promotes the family's incentives to transfer resources from child rearing to investment in land.

\section{Conclusions}

This paper examines the effects of a land reform by a family-optimization model that contains status seeking through the accumulation of relative per capita wealth. In such a case, the reform generates a higher rate of return to investment for peasant families. The outcome of this depends on preferences. If the appreciation of the social 
status from relative wealth is strong enough, then peasants limit their family size and invest in the improvement of land.

The puzzling demographic history in Europe provides supportive evidence for the land-reform hypothesis. Because of the land reform in the Great French Revolution 1789-1799, fertility declined in in the poor and rural France much earlier than in the rich and urbanized England.

Acknowledgments Open access funding provided by International Institute of Applied Systems Analysis (IIASA). Tapio Palokangas thanks IIASA (Laxenburg, Austria) for hospitality in Summer 2014 when the preliminary version of this paper was written.

Open Access This article is distributed under the terms of the Creative Commons Attribution 4.0 International License (http://creativecommons.org/licenses/by/4.0/), which permits unrestricted use, distribution, and reproduction in any medium, provided you give appropriate credit to the original author(s) and the source, provide a link to the Creative Commons license, and indicate if changes were made.

\section{Appendix A: Sharecropping}

In many agricultural economies, the landowner rents a farm by taking a share of the crop as a return. Since Stiglitz (1974) and Newbery (1977), economists explained this behavior by optimal risk-sharing contracts. On the basis of Strulik and Weisdorf's (2008) growth model, Vollrath (2012) built up a theory where a landowner makes a decision between fixed rent, fixed wage and sharecropping contracts to hire tenants. He showed that a fixed wage contract elicits the lowest and a fixed rent contract the highest fertility, with sharecropping being the intermediate case. He, however, assumed that peasants cannot improve the productivity of land and that agricultural labor can freely shift to the industrial sector, which was hardly possible in the 19th century. In our article, the peasant families are liquidity-constrained, having no option to move elsewhere. Thus, they have to allocate their labor between production and child rearing and finance improvements in the productivity of land by their personal savings.

We assume that the peasant family is able to hide some of its crop $Y$ at cost $E$, but the landowner can increase this cost $E$ by allocating resources $M$ to monitoring and policing. Let $\xi Y$ be the hidden crop and $(1-\xi) Y$ the revealed crop, where $\xi \in[0,1]$. We assume that the size of the family does not affect the ability to conceal the crop, but that such activity is subject to increasing costs. This means that the cost of hiding crop, $E$, is proportional to total crop $Y$, but increasing with respect to the ratio $\xi \doteq E / Y$ of hidden to total crop and the ratio $m \doteq M / Y$ of motoring costs to total crop $Y$. With the whole crop revealed, $\xi=0$, there is no cost, $E=0$. Given these assumptions, we obtain the cost function

$$
E=s(\xi, m) Y, \quad \frac{\partial s}{\partial \xi}>0, \quad \frac{\partial s}{\partial m}>0, \quad s(0, m)=0,
$$

where $s$ is the ratio of the cost $E$ to total crop $Y$. We assume that the function $s(\xi, m)$ twice differentiable, for convenience. 
If the landowner obtains the share $\chi \in[0,1]$ of the revealed crop $(1-\xi) Y$, then its rents amount to

$$
\Upsilon \doteq \chi(1-\xi) Y
$$

The peasant family earns crop $Y$ minus rents (16) and hiding costs (15):

$$
\Pi \doteq Y-\Upsilon-E=[1-(1-\xi) \chi-s(\xi, m)] Y .
$$

It maximizes its income (17) by its hiding proportion $\xi$, given cropsharing $\chi$, montoring costs $m$ and total crop $Y$. The first-order condition $\partial \Pi / \partial \xi=0$ is equivalent to $\chi=\frac{\partial s}{\partial \xi}(\xi, m)$. Differentiating this totally, we obtain the response function of the peasant family as follows:

$$
\xi(\chi, m), \quad \frac{\partial \xi}{\partial \chi}=1 / \frac{\partial^{2} s}{\partial \xi^{2}}, \quad \frac{\partial \xi}{\partial m}=-\frac{\partial^{2} s}{\partial \xi \partial m} / \frac{\partial^{2} s}{\partial \xi^{2}} .
$$

The landowner earns rents (16) minus monitoring costs $M=m Y$. Given the response function (18), this target becomes

$$
\Upsilon \doteq \chi(1-\xi) Y-M=[\chi-\xi(\chi, m) \chi-m] Y .
$$

The landowner maximizes (19) by cropsharing $\chi$ and the ratio $m$ of monitoring cost to total crop, given total crop $Y$. This implies that both $\chi$ and $m$ (and also $\xi$ ) are constants:

$$
(\chi, m)=\arg \max _{\chi, m} \Upsilon=\arg \max _{\chi, m}[\chi-\xi(\chi, m) \chi-m] .
$$

Given Eqs. 17 and 18, the income of the peasant family (net of hiding costs) relative to total crop is then a constant

$$
\gamma \doteq \Pi / Y=1-(1-\xi) \chi-s(\xi, m) \in(0,1) .
$$

Because an independent farmer has neither hiding costs $\xi$ nor the landowner's claims $\chi$, it earns total crop $\left.\Pi\right|_{\xi=\chi=0}=[1-s(0, m)] Y=Y$ [cf. (15) and (17)].

\section{Appendix B: Results (14)}

With the definition of the variable $k(t) \doteq b(t) /(\alpha-\gamma)$, we can transform the differential equations (8) and $\dot{b}=-\beta b$ [cf. (6)] into

$$
\begin{aligned}
& \dot{a}=\alpha F(1-q n, a)-c-(\alpha-\gamma) \beta k-n a, \quad a(0)=a_{0}, \quad \alpha>\gamma, \\
& \dot{k}=-\beta k, \quad k(0)=F\left(1-q n_{0}, a_{0}\right) / \sigma,
\end{aligned}
$$

where $a_{0}$ and $n_{0}$ are the initial steady-state values of $a$ and $n$. The family maximizes (11) by $c$ and $n$ subject to Eq. 20 at each moment of time. This leads to the Hamiltonian

$$
H=\log c+\theta \log n+\epsilon v(a-\underline{a})+\lambda[\alpha F(1-q n, a)-c-(\alpha-\gamma) \beta k-n a]-\zeta \beta k,
$$

where the co-state variables $\lambda$ and $\zeta$ evolve according to

$$
\begin{aligned}
& \dot{\lambda}=\rho \lambda-\frac{\partial H}{\partial a}=\left[\rho+n-\alpha F_{A}(1-q n, a)\right] \lambda-\varepsilon v^{\prime}(a-\underline{a}), \quad \lim _{t \rightarrow \infty} \lambda a e^{-\rho t}=0, \\
& \dot{\zeta}=\rho \zeta-\frac{\partial H}{\partial k}=(\rho+\beta) \zeta+(\alpha-\gamma) \beta \lambda, \quad \lim _{t \rightarrow \infty} \zeta k e^{-\rho t}=0 .
\end{aligned}
$$


The maximization of the Hamiltonian $(21)$ by the control variables $(c, n)$ for given $\lambda$ and $\zeta$ yields the first-order conditions

$$
\frac{\partial H}{\partial c}=\frac{1}{c}-\lambda=0, \quad \frac{\partial H}{\partial n}=\frac{\theta}{n}-\left[\alpha q F_{N}(1-q n, a)+a\right] \lambda=0 .
$$

Because the right-hand equation in Eq. 24 establishes a one-to-one correspondence from $\lambda$ to $n$, we can replace $\lambda$ by the fertility rate $n$ as the co-state variable. Furthermore, by the left-hand equation in Eq. 24, we can define per capita consumption $c$ as a function of $a$ and $n$ :

$$
\begin{aligned}
& c \doteq 1 / \lambda=z(a, n, \alpha) / \theta>0, \quad z(a, n, \alpha) \doteq\left[\alpha q F_{N}(1-q n, a)+a\right] n>0 \\
& z_{a} \doteq \frac{\partial z}{\partial a}=(\alpha q \underbrace{F_{N A}}_{+}+1) n>0, \quad z_{n} \doteq \frac{\partial z}{\partial n}=\underbrace{\alpha q F_{N}}_{+}+a-\alpha q^{2} n \underbrace{F_{N N}}_{-}>0 \\
& z_{\alpha} \doteq \frac{\partial z}{\partial \alpha}=q n F_{N}(1-q n, a)>0, \quad z=z_{\alpha} \alpha+a n>z_{\alpha} \alpha .
\end{aligned}
$$

Because the production function $F(N, A)$ is linearly homogenous [cf. (4)], its partial derivatives $F_{N}$ and $F_{A}$ are homogeneous of degree zero. From this, Eqs. 3, 12 and 25 it follows that

$$
\begin{aligned}
& 0=\left(N F_{N N}+A F_{N A}\right) / L=(1-q n) F_{N N}+a F_{N A}, \quad F_{N N}=-\frac{a}{1-q n} F_{N A}, \\
& 0=\left(N F_{N A}+A F_{A A}\right) / L=(1-q n) F_{N A}+a F_{A A}, \quad F_{A A}=-\frac{1-q n}{a} F_{N A}, \\
& -\alpha \underbrace{\frac{F_{A A}}{z_{a}}}_{+}=-\frac{\alpha}{n} \frac{F_{A A}}{1+\alpha q F_{N A}}=\frac{\alpha}{n a} \frac{(1-q n) F_{N A}}{1+\alpha q F_{N A}}=\frac{\alpha}{a n} \underbrace{\frac{\overbrace{1-q n}^{+}}{1 / F_{N A}+\alpha q}}_{+}<\frac{\alpha}{a n} \frac{1-q n}{\alpha q} \\
& =\frac{1}{a} \frac{1-q n}{q n}<\frac{\varepsilon}{\theta}, \quad \alpha F_{A A}+z_{a} \frac{\varepsilon}{\theta}>0, \\
& \frac{\varepsilon}{\theta} z_{n}-\alpha q F_{N A}-1>\frac{\varepsilon}{\theta}\left(a-\alpha q^{2} n F_{N N}\right)-\alpha q F_{N A}-1 \\
& =\underbrace{\frac{\varepsilon}{\theta} a}_{>1}-\frac{\varepsilon}{\theta} \alpha q^{2} n F_{N N}-\alpha q F_{N A}-1 \\
& >-\frac{\varepsilon}{\theta} \alpha q^{2} n F_{N N}-\alpha q F_{N A}=\left(-\frac{\varepsilon}{\theta} q n \frac{F_{N N}}{F_{N A}}-1\right) \alpha q F_{N A} \\
& =(\underbrace{\frac{\varepsilon}{\theta} \frac{q n a}{1-q n}-1}_{+}) \alpha q \underbrace{F_{N A}}_{+}>0 \text {. }
\end{aligned}
$$

Plugging the function (25) into (20) yields the differential equations

$$
\dot{a}=\alpha F(1-q n, a)-z(a, n, \alpha) / \theta-(\alpha-\gamma) \beta k-n a, \quad \dot{k}=-\beta k .
$$


Given Eqs. 13, 20 and 25, the first-equation in Eq. 28 has the properties:

$$
\begin{aligned}
& \frac{\partial \dot{a}}{\partial n}=-\alpha q F_{N}(1-q n, a)-a-\frac{z_{n}}{\theta}=-\frac{z}{n}-\frac{z_{n}}{\theta}<0, \quad \frac{\partial \dot{a}}{\partial a}=\alpha F_{A}(1-q n, a) \\
& -n-\frac{z_{a}}{\theta}, \\
& \frac{\partial \dot{a}}{\partial \alpha}=F(1-q n, a)-\frac{z_{\alpha}}{\theta}-\beta k=F(1-q n, a)\left[1-\frac{q n}{\theta} \frac{F_{N}(1-q n, a)}{F(1-q n, a)}\right. \\
& \left.-\frac{\beta k}{F(1-q n, a)}\right] \\
& =F(1-q n, a)\left[1-\frac{\eta}{\theta}-\frac{\beta k}{F(1-q n, a)}\right]=\underbrace{F(1-q n, a)}_{+}(\underbrace{1-\frac{\eta}{\theta}-\frac{\beta}{\sigma}}_{+})>0 \text {, } \\
& \frac{\partial \dot{a}}{\partial k}=(\gamma-\alpha) \beta<0 .
\end{aligned}
$$

On the assumption that all peasant families are identical, efficient land per family member is uniform in the economy, $\underline{a}=a$, in equilibrium. Given $\underline{a}=a$, Eqs. 11 and 25 , we can transform the differential (22) into

$$
\begin{aligned}
\rho+ & n-\alpha F_{A}(1-q n, a)-\frac{\varepsilon}{\theta} z(a, n, \alpha)=\rho+n-\alpha F_{A}(1-q n, a)-\frac{\varepsilon}{\lambda} \\
& =\rho+n-\alpha F_{A}(1-q n, a)-v^{\prime}(0) \frac{\varepsilon}{\lambda}=\frac{\dot{\lambda}}{\lambda}=\frac{d \log \lambda}{d t} \\
& =-\frac{d}{d t} \log z(a, n)=-\frac{z_{a}}{z} \dot{a}-\frac{z_{n}}{z} \dot{n} .
\end{aligned}
$$

Rearranging terms in Eq. 30, and noting Eqs. 25 and 29, we obtain the differential equation

$$
\dot{n}=\frac{z}{z_{n}}\left[\alpha F_{A}(1-q n, a)+\frac{\varepsilon}{\theta} z(a, n, \alpha)-n-\rho\right]-\frac{z_{a}}{z_{n}} \dot{a}
$$

with partial derivatives

$$
\begin{aligned}
& \frac{\partial \dot{n}}{\partial a}=\frac{z}{z_{n}}\left(\alpha F_{A A}+\frac{\varepsilon}{\theta} z_{a}\right)-\frac{z_{a}}{z_{n}} \frac{\partial \dot{a}}{\partial a}, \frac{\partial \dot{n}}{\partial n}=\frac{z}{z_{n}}\left(\frac{\varepsilon}{\theta} z_{n}-\alpha q F_{N A}-1\right)-\frac{z_{a}}{z_{n}} \frac{\partial \dot{a}}{\partial n}, \\
& \left.\frac{\partial \dot{n}}{\partial \alpha}\right|_{\dot{a}=\dot{n}=0}=\frac{z}{z_{n}}\left(F_{A}+\frac{\varepsilon}{\theta} z_{\alpha}\right)-\frac{z_{a}}{z_{n}} \frac{\partial \dot{a}}{\partial \alpha} .
\end{aligned}
$$

Finally, solving for $\lambda$ from the right-hand equation in Eq. 24, and plugging it into Eq. 23 yields the differential equation

$$
\dot{\zeta}=(\rho+\beta) \zeta+\frac{(\alpha-\gamma) \theta \beta / n}{\alpha q F_{N}(1-q n, a)+a} .
$$

We have a system of four differential Eqs. 28, 31 and 33 with predetermined variables $a$ and $b$, jump variables $n$ (representing $\lambda$ ) and $\zeta$ and the parameters $\alpha$ and $b(0)$. Given the production function $y=F(1-q n, a)$ [cf. (4)], per capita efficient land $a$ is always positive. Given the first-order conditions (24), per capita consumption $c$, the 
fertility rate $n$ and the co-state variable $\lambda$ are always positive. Given the right-hand equation in Eq. 28, $\lim _{t \rightarrow \infty} b=0$. Finally, given Eq. $23,\left.\zeta\right|_{\dot{\zeta}=0}=-\beta \lambda /(\rho+\beta)<0$. Thus, the values of $a, b, n$ and $\zeta$ in the steady state $\dot{a}=\dot{b}=\dot{n}=\dot{\zeta}=0$ are

$$
a^{*}>0, \quad b^{*}=0, \quad n^{*}>0, \quad \zeta^{*}<0 .
$$

At time $t=0$, the system Eqs. 28, 31 and 33 faces an increase of the family's crop share $\alpha$ from $\gamma$ to 1 . That system can be linearized in the neighborhood of the steady state $\left(a^{*}, b^{*}, n^{*}, \zeta^{*}\right)$ [cf. (29) and (32)]:

$$
\begin{aligned}
& 0=\left[\begin{array}{llll}
\frac{\partial \dot{a}}{\partial a} & \frac{\partial \dot{a}}{\partial k} & \frac{\partial \dot{a}}{\partial n} & \frac{\partial \dot{a}}{\partial \zeta} \\
\frac{\partial \dot{k}}{\partial a} & \frac{\partial \dot{k}}{\partial k} & \frac{\partial \dot{k}}{\partial n} & \frac{\partial \dot{k}}{\partial \zeta} \\
\frac{\partial \dot{n}}{\partial a} & \frac{\partial \dot{n}}{\partial k} & \frac{\partial \dot{n}}{\partial n} & \frac{\partial \dot{n}}{\partial \zeta} \\
\frac{\partial \dot{\zeta}}{\partial a} & \frac{\partial \dot{\zeta}}{\partial k} & \frac{\partial \dot{\zeta}}{\partial n} & \frac{\partial \zeta}{\partial \zeta}
\end{array}\right]\left[\begin{array}{l}
d a \\
d k \\
d n \\
d \zeta
\end{array}\right]+\left[\begin{array}{c}
\frac{\partial \dot{a}}{\partial \alpha} \\
\frac{\partial k}{\partial \alpha} \\
\frac{\partial \dot{n}}{\partial \alpha} \\
\frac{\partial \dot{\zeta}}{\partial \alpha}
\end{array}\right] d \alpha=\left[\begin{array}{cccc}
\frac{\partial \dot{a}}{\partial a} & \frac{\partial \dot{a}}{\partial b} & \frac{\partial \dot{a}}{\partial n} & 0 \\
0 & -\beta & 0 & 0 \\
\frac{\partial \dot{n}}{\partial a} & \frac{\partial \dot{n}}{\partial b} & \frac{\partial \dot{n}}{\partial n} & 0 \\
\frac{\partial \dot{\zeta}}{\partial a} & \frac{\partial \zeta}{\partial b} & \frac{\partial \dot{\zeta}}{\partial n} & \rho+\beta
\end{array}\right]\left[\begin{array}{c}
d a \\
d k \\
d n \\
d \zeta
\end{array}\right] \\
& +\left[\begin{array}{c}
\frac{\partial \dot{a}}{\partial \alpha} \\
0 \\
\frac{\partial \dot{n}}{\partial \alpha} \\
\frac{\partial \dot{\zeta}}{\partial \alpha}
\end{array}\right] d \alpha .
\end{aligned}
$$

We assume that the system has a saddle point: there is only one initial value $n(0)$ for the jump variable $n$ and one intial value $\zeta(0)$ for the jump variable $\zeta$, so that the system converges to the steady state $\left(a^{*}, k^{*}, n^{*}, \zeta^{*}\right)$. The saddle-point condition requires that the system must have two positive and two negative roots. The roots of this system $\mu_{1}, \mu_{2}, \mu_{3}$ and $\mu_{4}$ can be solved from the equation

$$
\begin{aligned}
& 0=\left|\begin{array}{cccc}
\frac{\partial \dot{a}}{\partial a}-\mu & \frac{\partial \dot{a}}{\partial b} & \frac{\partial \dot{a}}{\partial n} & 0 \\
0 & -\beta-\mu & 0 & 0 \\
\frac{\partial \dot{n}}{\partial a} & \frac{\partial \dot{n}}{\partial b} & \frac{\partial \dot{n}}{\partial n}-\mu & 0 \\
\frac{\partial \zeta}{\partial a} & \frac{\partial \dot{\zeta}}{\partial b} & \frac{\partial \dot{\zeta}}{\partial n} & \rho+\beta-\mu
\end{array}\right| \\
& =-(\beta+\mu)(\rho+\beta-\mu)\left|\begin{array}{ll}
\frac{\partial \dot{a}}{\partial a}-\mu & \frac{\partial \dot{a}}{\partial n} \\
\frac{\partial \dot{n}}{\partial a} & \frac{\partial \dot{n}}{\partial n}-\mu
\end{array}\right| \text {. }
\end{aligned}
$$

The first two roots are $\mu_{1}=-\beta<0$ and $\mu_{2}=\rho+\beta>0$. The remaining two roots $\mu_{3}$ and $\mu_{4}$ have different signs, if the determinant of the Jacobian for the subsystem of two equations $\dot{a}=0$ and $\dot{n}=0$ is negative [cf. (26), (27) and (29)]:

$$
\begin{aligned}
& 0>\left|\begin{array}{cc}
\frac{\partial \dot{a}}{\partial a} & \frac{\partial \dot{a}}{\partial n} \\
\frac{\partial n}{\partial a} & \frac{\partial n}{\partial n}
\end{array}\right|=\left|\begin{array}{cc}
\frac{\partial \dot{a}}{\partial a} \\
\frac{z}{z_{n}}\left(\alpha F_{A A}+\frac{\varepsilon}{\theta} z_{a}\right)-\frac{z_{a}}{z_{n}} \frac{\partial \dot{a}}{\partial a} & \frac{z}{z_{n}}\left(\frac{\varepsilon}{\theta} z_{n}-\alpha q F_{N A}-1\right)-\frac{z_{a}}{z_{n}} \frac{\partial \dot{a}}{\partial n}
\end{array}\right| \\
& =\frac{z}{z_{n}}\left|\begin{array}{cc}
\frac{\partial \dot{a}}{\partial a} & \frac{\partial \dot{a}}{\partial n} \\
\alpha F_{A A}+\frac{\varepsilon}{\theta} z_{a} & \frac{\varepsilon}{\theta} z_{n}-\alpha q F_{N A}-1
\end{array}\right| \\
& =(\underbrace{\frac{\varepsilon}{\theta} z_{n}-\alpha q F_{N A}-1}_{+}) \frac{\partial \dot{a}}{\partial a}-(\underbrace{\alpha F_{A A}+\frac{\varepsilon}{\theta} z_{a}}_{+}) \underbrace{\frac{\partial \dot{a}}{\partial n}}_{-} .
\end{aligned}
$$


This implies that the Jacobian of the whole system has a positive sign,

$$
\mathcal{J} \doteq\left|\begin{array}{cccc}
\frac{\partial \dot{a}}{\partial a} & \frac{\partial \dot{a}}{\partial b} & \frac{\partial \dot{a}}{\partial n} & 0 \\
0 & -\beta & 0 & 0 \\
\frac{\partial \dot{n}}{\partial a} & \frac{\partial \dot{n}}{\partial b} & \frac{\partial \dot{n}}{\partial n} & 0 \\
\frac{\partial \dot{\zeta}}{\partial a} & \frac{\partial \zeta}{\partial b} & \frac{\partial \dot{\zeta}}{\partial n} & \rho+\beta
\end{array}\right|=-(\rho+\beta) \beta \underbrace{\left|\begin{array}{cc}
\frac{\partial \dot{a}}{\partial a} & \frac{\partial \dot{a}}{\partial n} \\
\frac{\partial n}{\partial a} & \frac{\partial n}{\partial n}
\end{array}\right|}_{-}>0,
$$

and that

$$
\frac{\partial \dot{a}}{\partial a}<(\underbrace{\frac{\varepsilon}{\theta} z_{n}-\alpha q F_{N A}-1}_{+})^{-1}(\underbrace{\alpha F_{A A}+\frac{\varepsilon}{\theta} z_{a}}_{+}) \underbrace{\frac{\partial \dot{a}}{\partial n}}_{-}<0 .
$$

Noting Eqs. 25, 26, 27, 29, 32, 34, 35 and 36, we obtain

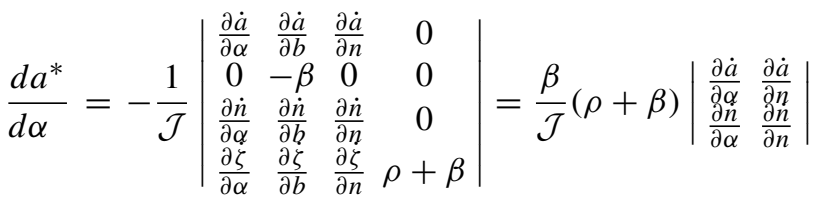

$$
\begin{aligned}
& =\frac{\beta}{\mathcal{J}}(\rho+\beta)\left|\begin{array}{c}
\frac{\partial \dot{a}}{\partial n} \\
\frac{z}{z_{n}}\left(F_{A}+\frac{\varepsilon}{\theta} z_{\alpha}\right)-\frac{z_{a}}{z_{n}} \frac{\partial \dot{a}}{\partial \alpha} \frac{z}{z_{n}}\left(\frac{\varepsilon}{\theta} z_{n}-\alpha q F_{N A}-1\right)-\frac{z_{a}}{z_{n}} \frac{\partial \dot{a}}{\partial n}
\end{array}\right| \\
& =\frac{\beta}{\mathcal{J}}(\rho+\beta) \frac{z}{z_{n}}\left|\begin{array}{cc}
\frac{\partial \dot{a}}{\partial \alpha} & \frac{\partial \dot{a}}{\partial n} \\
F_{A}+\frac{\varepsilon}{\theta} z_{\alpha} & \frac{\varepsilon}{\theta} z_{n}-\alpha q F_{N A}-1
\end{array}\right|=\underbrace{\frac{\beta}{\mathcal{J}}(\rho+\beta) \frac{z}{z_{n}}}_{+} \underbrace{\left|\begin{array}{c}
+- \\
++
\end{array}\right|>0,}_{+} \\
& \frac{d n^{*}}{d \alpha}=-\frac{1}{\mathcal{J}}\left|\begin{array}{cccc}
\frac{\partial \dot{a}}{\partial a} & \frac{\partial \dot{a}}{\partial b} & \frac{\partial \dot{a}}{\partial \alpha} & 0 \\
0 & -\beta & 0 & 0 \\
\frac{\partial \dot{n}}{\partial a} & \frac{\partial \dot{n}}{\partial b} & \frac{\partial \dot{n}}{\partial \alpha} & 0 \\
\frac{\partial \zeta}{\partial a} & \frac{\partial \dot{\zeta}}{\partial b} & \frac{\partial \dot{\zeta}}{\partial \alpha} & \rho+\beta
\end{array}\right|=\frac{\beta}{\mathcal{J}}(\rho+\beta)\left|\begin{array}{cc}
\frac{\partial \dot{a}}{\partial a} & \frac{\partial \dot{a}}{\partial \alpha} \\
\frac{\partial n}{\partial a} & \frac{\partial n}{\partial \alpha}
\end{array}\right| \\
& =\frac{\beta}{\mathcal{J}}(\rho+\beta)\left|\begin{array}{c}
\frac{\partial \dot{a}}{\partial a} \\
\frac{z}{z_{n}}\left(\alpha F_{A A}+\frac{\varepsilon}{\theta} z_{a}\right)-\frac{\partial \dot{a}}{z_{n}} \frac{\partial \dot{a}}{\partial a} \\
\frac{z}{z_{n}}\left(F_{A}+\frac{\varepsilon}{\theta} z_{\alpha}\right)-\frac{z_{a}}{z_{n}} \frac{\partial \dot{a}}{\partial \alpha}
\end{array}\right| \\
& =\frac{\beta}{\mathcal{J}}(\rho+\beta) \frac{z}{z_{n}}\left|\begin{array}{cc}
\frac{\partial \dot{a}}{\partial a} & \frac{\partial \dot{a}}{\partial \alpha} \\
\alpha F_{A A}+\frac{\varepsilon}{\theta} z_{a} & F_{A}+\frac{\varepsilon}{\theta} z_{\alpha}
\end{array}\right|=\underbrace{\frac{\beta}{\mathcal{J}}(\rho+\beta) \frac{z}{z_{n}}}_{+} \underbrace{\begin{array}{l}
-+\mid \\
++
\end{array} \mid}_{-}<0 .
\end{aligned}
$$

\section{References}

Acemoglu D, Cantoni D, Johnson S, Robinson JA (2010) From ancien regime to capitalism: the French Revolution as a natural experiment. In: Diamond J, Robinson JA (eds) Natural experiments in history. Harvard University Press, Boston

Bairoch P (1982) International industrialization levels from 1750 to 1980. J Eur Econ History 11(2):269_ 333

Becker GS (1960) An economic analysis of fertility. In: Demographic and economic changes in developed countries. Princeton University Press, Princeton, pp 209-230

Bonneuil N (1997) Transformation of the French demographic landscape. Clarendon Press, Oxford, pp 1806-1906 
Chesnais J-C (1992) The demographic transition: stages, patterns and economic implications. Oxford University Press, Oxford

Cleland J, Wilson C (1987) Demand theories of the fertility transition: an iconoclastic view. Popul Stud 41(1):5-30

Coale A (1986) The decline of fertility in Europe since the eighteenth century as a chapter in demographic history. In: Coale A, Watkins S (eds) The decline of fertility in Europe. Princeton University Press, Princeton, pp 1-30

Coale A, Watkins S (1986) The decline of fertility in Europe. Princeton University Press, Princeton

Corneo G, Jeanne O (2001) On relative-wealth effects and long-run growth. Res Econ 55(4):349358

Cummins NJ (2013) Marital fertility and wealth during the fertility transition: rural France, 1750-1850. Econ Hist Rev 66(2):449-476

de la Croix D, Doepke M (2003) Inequality and growth: why differential fertility matters. Amer Econ Rev 93(4):1091-1113

Gonzàlez-Bailòn S, Murphy T (2013) The effects of social interactions on fertility decline in nineteenthcentury France: an agent-based simulation experiment. Popul Stud 67(2):135-155

Easterlin R (1975) An economic framework for fertility analysis. Stud Fam Plan 6(3):54-63

Festy P (1979) La féconfité des pays occidentaux de 1870 à 1970. Presses Universitaires de France, Paris

Fisher WH, Hof FX (2005) Status seeking in a small open economy. J Macroecon 27(2):209_ 232

Galor O, Weil DN (2000) Population, technology, and growth: From Malthusian stagnation to the demographic transition and beyond. Amer Econ Rev 90(4):806-826

Galor O, Moav O, Vollrath D (2009) Inequality in land ownership, the emergence of human capital promoting institutions and the great divergence. Rev Econ Stud 76(1):143-179

Guinnane TW (2011) The historical fertility transition: a guide for economists. J Econ Lit 49(3):589-614

Kurz M (1968) Optimal economic growth and wealth effects. Int Econ Rev 9(3):348-357

Lehmijoki U, Palokangas T (2009) Population growth overshooting and trade in developing countries. J Popul Econ 22:43-56

Lehmijoki U, Palokangas T (2010) Trade, population growth, and the environment in developing countries. J Popul Econ 23(4):1351-1373

Lehmijoki U, Palokangas T (2014) Landowning, status and population growth. Pages In: Moser E, Semmler W, Tragler G, Veliov VM (eds) Dynamic optimization in environmental economics. Springer Verlag, Heidelberg, pp 315-328

Lucas REJ (2002) Lectures on economic growth. Harward University Press, Cambridge

Maddison A (1995) Monitoring the world economy, OECD, Paris

The Maddison-Project (2013) http://www.ggdc.net/maddison/maddison-project/home.htm, 2013 version

Malthus TR (1798) An essay on the principle of population, as it affects the future improvement of society with remarks on the speculations of Mr. Godwin, M. Condorcet, and other writers. Printed For J. Johnson, In St. Paul's Church-Yard, London

Mokyr J (2005) Long-term economic growth and history of technology. In: Aghion P, Durlauf S (eds) Handbooks of economic growth 1b, chapter 17. Elsevier, Amsterdam

Newbery DMG (1977) Sharecropping and uncertain labor markets. Rev Econ Stud 44(3):585-594

Notestein F (1945) Population - the long view. In: Schultz T (ed) Food for the world. University of Chicago Press, Chicago, pp 36-57

Razin A, Ben-Zion U (1975) An intergenerational model of population growth. Amer Econ Rev 65:923933

Stiglitz J (1974) Incentives and risk sharing in sharecropping. Rev Econ Stud 41:219-255

Strulik H, Weisdorf J (2008) Population, food, and knowledge: a simple unified growth theory. J Econ Growth 13:195-216

Sullivan RJ (1995) Trends in the agricultural labor force. In: Simon JL (ed) The state of humanity, chapter 12. Blackwell, Massachussetts

Sutherland DMG (2002) Peasants, lords, and Leviathan: Winners and losers from the abolition of French feudalism 1780-1820. J Econ Hist 62(1):1-24

van de Kaa D (1996) Anchored narratives: the story and findings of half a century of research into the determinants of fertility. Popul Stud 50(3):389-432

Vollrath D (2012) Land tenure, population, and long-run growth. J Popul Econ 25:833-852

Weir DR (1994) New estimates of nuptiality and marital fertility in France, 1740-1911. Popul Stud 48(2):307-331 